\title{
IGUALDADE E DIFERENÇAS NA ESCOLA - COMO ANDAR NO FIO DA NAVALHA*
}

Maria Teresa Eglér Mantoan**

\section{RESUMO}

O ensino escolar brasileiro, nos debates atuais sobre inclusão, tem diante de si o desafio de encontrar soluções que respondam à questão do acesso e da permanência dos alunos nas suas instituições educacionais. Algumas escolas públicas e particulares já adotaram ações nessa direção ao proporem mudanças na sua organização pedagógica, de modo a reconhecer e valorizar as diferenças, sem discriminar os alunos e/ou segregá-los. Apesar das resistências, cresce a adesão de redes de ensino, de escolas e de professores, pais e instituições dedicadas à inclusão de pessoas com deficiência, o que denota o efeito dessas novas experiências e, ao mesmo tempo, motiva questionamentos. Com a intenção de explorar esse debate sobre inclusão e escolaridade, vamos analisar alguns pontos polêmicos que cercam essa situação de mudança, nos dias atuais, diante de inovações propostas por políticas educacionais e práticas escolares que envolvem o ensino regular e especial. Mais do que avaliar os argumentos contrários e favoráveis às políticas educacionais inclusivas, abordaremos, entre seus aspectos mais polêmicos, a complexa relação de igualdade e diferenças, que envolve o entendimento, a elaboração de tais políticas e todas as iniciativas visando à transformação das escolas para se ajustarem aos princípios inclusivos de educação.

Palavras-chave: inclusão escolar; igualdade de oportunidades; direito à diferença.

\footnotetext{
* Artigo recebido em 12/6/2006 e aprovado em 22/8/2006.

** Pedagoga, doutora em Educação; professora dos cursos de graduação e de pós-graduação da Faculdade de Educação da Universidade Estadual de Campinas; coordenadora do Laboratório de Estudos e Pesquisas em Ensino e Diversidade-LEPED/Unicamp. Email: tmantoan@unicamp.br
} 


\section{A QUESTÃO DA IGUALDADE/DIFERENÇAS}

A inclusão escolar está articulada a movimentos sociais mais amplos que exigem maior igualdade e mecanismos mais eqüitativos no acesso a bens e serviços. Associada a sociedades democráticas que estão pautadas no mérito individual e na igualdade de oportunidades, a inclusão propõe a desigualdade de tratamento como forma de restituir uma igualdade que foi rompida por formas segregadoras do ensino especial e regular.

Fazer valer o direito à educação para todos não se limita a cumprir o que é de lei e aplicá-la, sumariamente, às situações discriminadoras. $\mathrm{O}$ assunto merece um entendimento mais fundo dessa questão de justiça.

A escola justa e desejável para todos não se sustenta unicamente no fato de os homens serem iguais e nascerem iguais. Para Bobbio (1997), a igualdade natural não tem um significado unívoco, mas tantos quantos forem as respostas às questões: Igualdade entre quem? Igualdade em $q u \hat{e}$ ? A extensão desse valor, portanto, precisa ser considerada, para não entendermos que todos os homens sejam iguais em tudo!

Mesmo os que defendem o igualitarismo até as últimas conseqüências entendem que não se pode ser igual em tudo. Bobbio (idem, p. 25) considera que Rousseau, em seu Discurso sobre a origem da desigualdade entre os homens, estabeleceu uma diferenciação entre desigualdades naturais (produzidas pela natureza) e desigualdades sociais (produzidas pelas relações de domínio econômico, espiritual, político). Para alcançar os ideais igualitários seria necessário eliminar as segundas, não as primeiras, pois estas são benéficas ou mesmo moralmente indiferentes.

A inclusão, como os demais movimentos provocados por grupos que historicamente foram excluídos da escola e da cidadania plena, é uma denúncia ao que Hanna Arendt (1978) chamou de abstrata nudez, pois é inovação incompatível com a abstração das diferenças, para chegar a um sujeito universal. Quando entendemos que não é a universalidade da espécie que define um sujeito, mas as suas peculiaridades, ligadas ao sexo, etnia, origem, crenças, tratar as pessoas diferentemente pode enfatizar suas diferenças, assim como tratar igualmente os diferentes pode esconder as suas especificidades e excluí-las do mesmo modo e, assim sendo, ser gente é correr sempre o risco de ser diferente.

O dilema, como nos lembra Pierucci (1999), está em mostrar ou esconder as diferenças. 
Como enfrentá-lo nas escolas que primam pela homogeneização dos alunos e que usam a desigualdade social como argumento em favor da exclusão?

Para instaurar uma condição de igualdade nas escolas não se concebe que todos os alunos sejam iguais em tudo, como é o caso do modelo escolar mais reconhecido ainda hoje. Temos de considerar as suas desigualdades naturais e sociais e só estas últimas podem/devem ser eliminadas.

Se a igualdade traz problemas, as diferenças podem trazer muito mais!

As políticas educacionais atuais confirmam em muitos momentos o projeto igualitarista e universalista da Modernidade. No geral, elas participam do esforço da Modernidade para superar o que se chamou de estado da natureza, a fim de domesticar os que diferem do padrão. Como incluir as diferenças a partir de um plano racional de atuação que os extingue ou os põe de lado "como refugo que escapa à definição?" (BAUMAN, 1999, p. 15).

O discurso da Modernidade, movimento que se caracteriza, principalmente, por uma guerra à ambivalência e por um esforço racional de ordenar o mundo, os seres humanos, a vida, estendeu suas precauções contra o imprevisível, a ambigüidade e os demais riscos à ordem e à unicidade, repetindo que todos são iguais, todos são livres, são isto, são aquilo, mas um todos padronizado, dentro de seus pressupostos disciplinadores (BAUMAN, 1999).

Esse discurso sustenta a organização pedagógica escolar e, por seus parâmetros, o aluno diferente (porque ele é indefinido, incoerente, indeterminado) desestabiliza o pensamento moderno da escola, na sua ânsia pelo lógico, pela negação das condições que produzem as diferenças, que são as matrizes da nossa identidade.

A diferença propõe o conflito, o dissenso e a imprevisibilidade, a impossibilidade do cálculo, da definição, a multiplicidade incontrolável e infinita. Essas situações não se enquadram na cultura da igualdade das escolas, introduzindo nelas um elemento complicador que se torna insuportável e delirante para os reacionários que as compõem e as defendem tal como ela ainda se mantém. Porque a diferença é difícil de ser recusada, negada, desvalorizada. Se ela é recusada, negada, desvalorizada, há que assimilá-la ao igualitarismo essencialista e, se aceita e 
valorizada, há que mudar de lado e romper com os pilares nos quais a escola tem se firmado até agora.

A igualdade abstrata não propiciou a garantia de relações justas nas escolas. A igualdade de oportunidades, que tem sido a marca das políticas igualitárias e democráticas no âmbito educacional, também não consegue resolver o problema das diferenças nas escolas, pois elas escapam ao que essa proposta propõe diante das desigualdades naturais e sociais.

Em sua obra Teoria da justiça, Rawls (2002) opõe-se às declarações de direito do mundo moderno, que igualaram os homens em seu instante de nascimento e estabeleceram o mérito e o esforço de cada um como medida de acesso e uso de bens, recursos disponíveis e mobilidade social. Para esse filósofo político, a liberdade civil com suas desigualdades sociais, e a igualdade de oportunidades com suas desigualdades naturais, são arbitrárias do ponto de vista moral; ele propôs uma política da diferença, estabelecendo a identificação das diferenças como uma nova medida da igualdade. Ele assim se pronunciou:

Assim, somos levados ao princípio da diferença, se desejamos montar o sistema social de modo que ninguém ganhe ou perca devido ao seu lugar arbitrário na distribuição de dotes naturais ou à sua posição inicial na sociedade sem dar ou receber benefícios compensatórios em troca. (p. 108)

Caminhando na mesma direção das propostas escolares inclusivas, o referido autor defende que a distribuição natural de talentos ou a posição social que cada indivíduo ocupa não são justas nem injustas. $O$ que as torna justas ou não são as maneiras pelas quais as instituições (no caso, as educacionais) fazem uso delas. Ele sugere, então, uma igualdade democrática, que combina o princípio da igualdade de oportunidades com o princípio da diferença (2002, p. 79).

A sugestão de Rawls tem opositores, por ser contra a noção de mérito. Para os que lutam por uma escola verdadeiramente inclusiva, na mesma linha argumentativa de Rawls, o merecimento não parece aplicarse devidamente aos que já nascem em uma situação privilegiada socialmente, aos que já tiveram a oportunidade de se desenvolver a partir das melhores condições de vida e de aproveitamento de suas potencialidades; o mérito deve ser proporcional ao ponto de partida de cada um. 
Ao combinar os dois princípios, Rawls reconhece que as desigualdades naturais e sociais são imerecidas e precisam ser reparadas e compensadas, e o princípio da diferença é o que garante essa reparação, visando à igualdade.

A igualdade de oportunidades é perversa quando garante o acesso, por exemplo, à escola comum de pessoas com alguma deficiência de nascimento ou de pessoas que não têm a mesma possibilidade das demais de passar pelo processo educacional em toda a sua extensão, por problemas alheios aos seus esforços. Mas não lhes assegura a permanência e o prosseguimento da escolaridade em todos os níveis de ensino.

Mais um motivo para se firmar a necessidade de repensar e de romper com o modelo educacional elitista de nossas escolas e de reconhecer a igualdade de aprender, como ponto de partida, e as diferenças no aprendizado, como processo e ponto de chegada.

A esse propósito é fundamental a contribuição de Joseph Jacotot. ${ }^{1}$ Ele nos trouxe um olhar original sobre a igualdade que até então se emaranhava nas questões de direito, de política, de promessas constitucionais. Afirmava que a igualdade não seria alcançada a partir da desigualdade, como se espera atingi-la, até hoje, nas escolas; acreditava em uma outra igualdade, a igualdade de inteligências. Jacotot defendia o ser humano como ser cognoscente, capaz de aprender, de conhecer, e defendia essa capacidade de toda submissão - uma inteligência não pode submeter uma outra. Em uma palavra, a emancipação da inteligência proviria dessa igualdade de capacidade de aprender, que vem antes de tudo, que é ponto de partida para qualquer tipo ou nível de aprendizagem. O professor, portanto, não poderia negar essa capacidade, esse "lugar do saber" que cada aluno tem de ocupar diante de todo o ensino ministrado, pois, ao fazê-lo, estaria ferindo esse princípio de igualdade intelectual e, portanto, embrutecendo-o.

Vale citar algumas das suas idéias para entrever o alcance da pedagogia desse mestre para os nossos tempos de inclusão educacional:

"A igualdade não é um objetivo a atingir, mas um ponto de partida, uma suposição a ser mantida em qualquer circunstância."

"Há desigualdade nas manifestações da inteligência, segundo a energia mais ou menos grande que a vontade comunica à inteligência para descobrir e combinar relações novas, mas não há hierarquia de capacidade intelectual." 
As grandes lições deste mestre, embora enfoquem a igual capacidade de conhecer, constituem mais um argumento em favor da necessidade de combinar igualdade com as diferenças e de nos distanciarmos dos que se apegam unicamente à cultura da igualdade liberal de oportunidades e do mérito para defender a escola do seu caráter excludente, que bane os que, por desigualdades significativas de nascimento e/ou desigualdades sociais, não conseguem preencher os requisitos de um padrão de aluno previamente estipulado.

A escola insiste em afirmar que os alunos são diferentes quando se matriculam em uma série escolar, mas o objetivo escolar, no final desse período letivo, é que eles se igualem em conhecimentos a um padrão que é estabelecido para aquela série, caso contrário serão excluídos por repetência ou passarão a freqüentar os grupos de reforço e de aceleração da aprendizagem e outros programas embrutecedores da inteligência.

A indiferença às diferenças está acabando, passando da moda. Nada mais desfocado da realidade atual do que ignorá-las. Nada mais regressivo do que discriminá-las e isolá-las em categorias genéricas, típicas da necessidade moderna de agrupar os iguais, de organizar pela abstração de uma característica qualquer, inventada, e atribuída de fora.

Mas é preciso estar atento, pois combinar igualdade e diferenças no processo escolar é andar no fio da navalha. O certo, porém, é que os alunos jamais deverão ser desvalorizados e inferiorizados pelas suas diferenças, seja nas escolas comuns, seja nas especiais. Esses espaços educacionais não podem continuar sendo lugares da discriminação, do esquecimento, que é o ponto final dos que seguem a rota da proposta da eliminação das ambivalências com que as diferenças afrontam a Modernidade.

\section{FAZER VALER O DIREITO À EDUCAÇÃO NO CASO DE PESSOAS COM DEFICIÊNCIA}

Nosso sistema educacional, diante da democratização do ensino, tem vivido muitas dificuldades, no sentido de equacionar uma relação complexa, que é a de garantir escola para todos, mas de qualidade. É inegável que a inclusão coloca ainda mais lenha na fogueira e que o problema escolar brasileiro é dos mais difíceis, diante do número de alunos que temos de atender, das diferenças regionais, do conservadorismo das escolas, entre outros. 
A verdade é que o ensino escolar brasileiro continua aberto a poucos, e essa situação se acentua drasticamente no caso dos alunos com deficiência. O fato é recorrente em qualquer ponto de nosso território, na maior parte de nossas escolas, públicas ou particulares, e em todos os níveis de ensino, mas principalmente nas etapas do ensino básico: educação infantil, ensino fundamental e médio.

A inclusão escolar tem sido mal compreendida, principalmente no que diz respeito ao seu apelo a mudanças nas escolas comuns e especiais. Sabemos, contudo, que sem essas mudanças não garantiremos a condição de nossas escolas receberem, indistintamente, a todos os alunos, oferecendo-lhes condições de prosseguir em seus estudos, segundo a capacidade de cada um, sem discriminações e espaços segregados de educação.

Muitos argumentos têm sido utilizados para combater os que lutam em favor da inclusão escolar, até mesmo há os que nos acusam de promovê-la com irresponsabilidade! A eles temos de responder com o sentido inovador e revolucionário dessa proposta educacional.

Artigos, livros, palestras - que tratam devidamente do tema insistem na transformação das práticas de ensino comum e especial para a garantia da inclusão, e é nítida essa nossa preocupação, pois a inclusão é, ao mesmo tempo, motivo e conseqüência de uma educação aberta às diferenças e de qualidade.

Temos a Constituição de 1988 e leis educacionais que apóiam a necessidade de reconstruir a escola brasileira sob novos enfoques educacionais e que nos conclamam a uma virada para melhor de nosso ensino. Há apoio legal suficiente para mudar, mas só temos tido, até agora, muitos entraves nesse sentido.

Em recente artigo, que escrevi para uma revista especializada, citei alguns deles: a resistência das instituições especializadas a mudanças de qualquer tipo; a neutralização do desafio à inclusão, por meio de políticas públicas que impedem que as escolas se mobilizem para rever suas práticas homogeneizadoras, meritocráticas, condutistas, subordinadoras e, em conseqüência, excludentes; o preconceito, o paternalismo em relação aos grupos socialmente fragilizados, como o das pessoas com deficiência. Há ainda a considerar outras barreiras que impedem a transformação de nossas escolas - o corporativismo dos que se dedicam às pessoas com deficiência e a outras minorias, principalmente dos que tratam de pessoas com deficiência mental; a ignorância de muitos pais, a 
fragilidade de grande maioria deles diante do fenômeno da deficiência de seus filhos.

Precisamos de apoio e de parcerias para enfrentar essa tarefa de todos - um ensino de qualidade. Temos sofrido muita oposição e resistência dos que deveriam estar nos apoiando. Falta vontade de mudar.

$\mathrm{Na}$ verdade, resiste-se à inclusão escolar porque ela nos faz lembrar que temos uma dívida a saldar em relação aos alunos que excluímos pelos motivos mais banais e inconsistentes, apoiados por uma organização pedagógico-escolar que se destina a alunos ideais, padronizados, por uma concepção de normalidade e de eficiência arbitrariamente definida.

Sabemos que alunos com e sem deficiência, que foram e são ainda excluídos das escolas comuns, devem estar inseridos nessas escolas, e há muito tempo, ou seja, desde que o ensino fundamental é obrigatório para os alunos em geral. Se os pais, professores e dirigentes educacionais não tinham conhecimento do direito de todos à educação comum, há hoje documentos e uma ação corajosa do movimento escolar inclusivo, que estão cumprindo o seu dever de alertar os educadores e os pais nesse sentido.

A Lei de Diretrizes e Bases da Educação Nacional (LDBEN), de 1996, deixa claro que o ensino especial é uma modalidade e, como tal, deve perpassar o ensino comum em todos os seus níveis - da escola básica ao ensino superior. Haja vista as portarias e demais instrumentos pelos quais a educação garante aos alunos universitários a presença de intérpretes, tecnologia assistiva e outros recursos, em sala de aula comum. Há que assegurar não apenas o acesso, mas a permanência e o prosseguimento do estudo desses alunos, e não retirar do Estado, por qualquer motivo, essa obrigação, exigindo, postulando o cumprimento das leis, para atender às necessidades educacionais de todos.

Se ainda não é do conhecimento geral, é importante que se saiba que as escolas especiais complementam e não substituem a escola comum. $\mathrm{E}$ as nossas leis prescrevem esse (novo?) fato há quase duas décadas. Elas se destinam ao ensino do que é diferente da base curricular nacional, mas que garante/possibilita ao aluno com deficiência a aprendizagem desses conteúdos, quando incluídos nas turmas comuns de ensino regular. Oferece atendimento educacional especializado, que não tem níveis, seriações, certificações.

Falta às escolas especiais e às instituições para pessoas com deficiência a compreensão do papel formador da escola comum, que 
jamais será exercido em um meio educacional segregado, assim como lhes falta a consciência de que as escolas especiais se descaracterizaram, perderam sua identidade, bem como os profissionais que nelas lecionam, particularmente os que são professores especializados. De fato, ora esses profissionais atuam como orientadores de professores de escolas comuns, onde estão incluídos alguns alunos dessas instituições, ora dão aulas como professores de ensino regular, mas em escolas especiais! Tudo se confundiu de tal modo que é difícil até para quem quer compreender o que significa atender a alunos com deficiência nas suas necessidades educacionais como um todo, sejam as especificamente escolares, sejam as relativas ao atendimento complementar especializado. Se a escola é especial, parece coerente que ela não seja comum, mas o que ocorre é que elas acabam sendo nem uma coisa nem outra.

Nossa obrigação é fazer valer o direito de todos à educação, e não precisamos ser corajosos para defender a inclusão, porque estamos certos de que não corremos nenhum risco ao propor que alunos com e sem deficiência deixem de freqüentar ambientes educacionais à parte, que segregam, discriminam, diferenciam pela deficiência, excluem - como é próprio das escolas especiais.

O que falta às escolas especiais, como substitutas das comuns, é muito mais do que a soma das carências das escolas comuns. Falta-lhes o primordial das escolas, isto é, o ambiente apropriado de formação do cidadão.

Em inúmeras publicações - artigos, livros, entrevistas, palestras -, indicamos as mudanças necessárias para que o acesso, a permanência e o prosseguimento dos estudos de alunos com deficiência na escola comum se concretizem; o assunto já é sobejamente conhecido dos educadores e gestores da educação escolar em todos os níveis de ensino. Tanto as escolas especiais quanto as comuns precisam se reorganizar e melhorar o atendimento que dispensam a seus alunos. Precisamos lutar por essas mudanças, e por movimentos que têm como fim virar essas escolas do avesso. Ambas precisam sair do comodismo em que se encontram, e a inclusão, especialmente quando se trata de alunos com deficiência, é o grande mote para empreender essa reviravolta.

É um engano pensar que as escolas de países mais avançados e mais ricos são melhores do que as nossas. Elas podem apresentar índices menores de desaprovação, pois esses países não têm problemas de superpopulação na idade escolar e de aumento constante desse segmento, 
principalmente nas grandes cidades. Mas os problemas que causam essa desaprovação são os mesmos em todo o mundo. Outro ledo engano é pensar que nesses países a inclusão já acontece, especialmente no que diz respeito à deficiência mental.

Quanto mais um país se sofistica intelectual e culturalmente, mais essas pessoas são desvalorizadas nas suas competências laborais e acadêmicas e mais se amplia a rede de proteção (à deficiência ou às pessoas em geral?) e com isso a segregação aumenta e recrudesce.

Se a inclusão for uma das razões fortes de mudança, temos condições de romper com os modelos conservadores da escola comum brasileira e iniciarmos um processo gradual, porém firme, de redirecionamento de suas práticas, no sentido de oferecer melhor qualidade de ensino para todos. Muito já teria sido feito, não fossem os entraves com que sempre deparamos: ora são as instituições especializadas, ora as corporações, ora as autoridades de ensino, os defensores públicos, enfim, sempre temos de perder o tempo de trabalhar em favor de uma escola de melhor qualidade para dedicar-nos a defender o óbvio.

As escolas especiais também estão perdendo o seu tempo de mudar.

Existem inúmeras redes de escolas comuns e também algumas escolas especiais que há tempo estão vivendo esse processo de transformação e eliminando seus métodos excludentes de ensinar. Elas já estão se adequando e cumprindo a Constituição e a LDBEN e pondo em ação práticas que exigem inovações educacionais, como a inclusão escolar. Há muitas que já estão assegurando aos alunos com deficiência, seja nas escolas comuns, seja nas especiais, o atendimento educacional especializado, em horário diferente ao da escola comum.

O processo de transformação da escola comum é lento e não pretende gerar maior marginalização do que já existe, abertamente, nas escolas especiais, tais como hoje se apresentam. Para que haja um processo de mudança, cujo movimento ruma para novas possibilidades para o ensino comum e especial, há que existir uma ruptura com o modelo antigo de escola. Porque não há como caminhar com um pé em cada canoa.

O ensino escolar comum e o despreparo dos professores, por sua vez, não podem continuar sendo justificativa dos que querem escapar da inclusão escolar, pelos mais diferentes motivos. De fato, esse despreparo dos professores e das escolas tranqüiliza e é o argumento favorito de 
muitos pais de crianças e jovens com deficiência, que acharam uma boa saída para fugir da inclusão. Felizmente, nem todos são tão ingênuos que conseguem "engolir" essa argumentação. Surpreende-me que ela ainda esteja sendo utilizada!

Como prepará-los sem que possam viver a experiência e o desafio das diferenças nas suas salas de aula? Que motivos teriam para se mobilizar? Para buscar novas respostas educacionais?

Em uma palavra, a inclusão não pode mais ser ignorada. Ela está tão presente que motiva pressões descabidas, que pretendem nos desestabilizar a qualquer custo.

Aos contra-sensos pelos quais a escola inclusiva é tão combatida, vamos responder com o sentido pleno que damos à escola que queremos para todos os brasileiros - uma escola que reconhece e valoriza as diferenças.

\section{NOTA}

1. Este professor de idéias extravagantes para sua época e para a atualidade viveu de 1770 a 1840 . Foi trazido do esquecimento da história da pedagogia do século 19 por Jacques Rancière, autor do livro $O$ mestre ignorante - cinco lições sobre a emancipação intelectual, publicado no Brasil em 2002 pela editora Autêntica de Belo Horizonte-MG e que nos conta a história e as idéias ousadas e inovadoras desse educador.

\section{ABSTRACT}

In the debate on inclusion, Brazilian schooling faces the challenge of finding solutions to the problems of student access and permanence at educational institutes. Some public and private schools have already taken steps in this direction. Through proposals for change in their pedagogical organization they seek to recognize and appreciate difference without discrimination or segregation. In spite of a certain resistance more and more teaching networks, schools, teachers, parents and institutes dedicated to the inclusion of the disabled are coming on board, which denotes both how effective these new experiences are as well as raising questions. With a view to further exploring this debate we analyze some of the controversial issues involved in this present fluid situation when faced with the innovations proposed by educational policy and school practice involving both regular and special education. More than evaluating the pros and cons of inclusive educational policies, the text studies one of the most 
controversial aspects, namely, that of the complex relationship of equality and difference, which involves understanding, drawing up such policies and all the initiatives for transforming schools to adjust to inclusive educational principles.

Key words: inclusion in school; equality of opportunity; right to be different.

\section{REFERÊNCIAS}

ARENDT, H. O sistema totalitário. Lisboa: Publicações Dom Quixote, 1978.

BAUMAN, Z. Modernidade e ambivalência. Rio de Janeiro: Jorge Zahar Editores, 1999.

BOBBIO, N. Igualdade e liberdade. 3. ed. Rio de Janeiro: Ediouro, 1997.

PIERUCCI, A. F. Ciladas da diferença. São Paulo: Editora 34, 1999.

RAWLS, J. Uma teoria da justiça. 2. ed. São Paulo: Martins Fontes, 2002. 